\title{
Self-recognition among institutionalized profoundly retarded males: A replication
}

\author{
LARRY P. HARRIS \\ University of Texas, Austin, Texas 78712
}

\begin{abstract}
Eighteen profoundly retarded males were pretested for the ability to recognize their mirrored and photographic images. Nine subjects were then given mirror training for $10 \mathrm{~min}$ daily on 13 consecutive days. Posttest results indicated no improvement in recognition as measured. These findings are similar to those reported by Pechacek, Bell, Cleland, Baum, and Boyle (1973) indicating that (1) profoundly mentally retarded males rank somewhat below adolescent chimpanzees (e.g., Gallup, 1970) and orangutans (Lethmate \& Dücker, cited in Gallup, Boren, Gagliardi, \& Wallnau, in press) in the ability to make "self-directed" responses to their mirrored images; and (2) mirror training does not transfer to self-photograph discrimination for which comparative data are unavailable.
\end{abstract}

Pechacek, Bell, Cleland, Baum, and Boyle (1973) reported negative results from two experiments which undertook to determine whether profoundly mentally retarded (PMR) institutionalized males could be taught, through mirror exposure, to recognize their mirrored or photographic images. These researchers employed a paradigm developed by Gallup (1970) for assessing mirror recognition of self among adolescent, feral chimpanzees. Briefly, the Pechacek et al. (1973) main experiment entailed pre- and posttesting as follows: A red dye marker was applied to the foreheads of sleeping subjects; after the subjects were awakened, they were individually exposed to a full-length mirror; if a subject brushed at the marker, this betrayed "self-recognition." Between testing sessions, half of the subjects were exposed to a mirror on each of 3 consecutive days for three $15-\mathrm{min}$ sessions daily; the remaining subjects served as controls and received an identical amount of interaction with an experimenter but no mirror exposure.

In the second study, similar subjects were pre- and posttested for the ability to select a Polaroid snapshot of self from among three photographs placed on a tray. Between testing sessions, half of the subjects were "exposed to a mirror for an average of $3.5 \mathrm{~min}$ on 3 alternate days" (p. 329). Results again failed to reveal any recognition.

The present investigation was conceived as a replication of the above with the following modifications: (1) The same subjects were tested before and after training with both the mirror and photographic measures; (2) mirror training was conducted for one

The author wishes to acknowledge the critical assistance provided by Charles C. Cleland, Professor of Special Education and Educational Psychology, University of Texas at Austin, and the residents, staff, and administrators of the Travis State School, particularly L. E. Birdsong, III, Unit Director, and Loyce Reese, Building Charge. This paper is sponsored by Gordon G. Gallup, Jr., who takes full editorial responsibility for its content.
10 -min session on each of 13 consecutive days; (3) two larger $(12.70 \times 20.32 \mathrm{~cm})$ color photographs were used per subject-a whole-body picture taken with the subject in a controlled position and a head-and-shoulders vignetted print enlarged from the same negative; (4) after the first week of training, a three-mirror display was used; and (5) a green mark was substituted for the red to avoid confusion with medication frequently applied to forehead cuts. It was hypothesized that these modifications would lead to demonstrations of self-recognition as predicted by mirror-image stimulation theory (Gallup, 1968) and studies which have reported the presence of the ability among MA-matched normal infants (e.g., Gesell \& Ames, 1947).

\section{METHOD}

\section{Subjects}

From a dormitory housing PMR males at a large state school for the retarded, 20 subjects with no reported visual or hearing losses and Vineland SQs of under 20 were selected. The subjects were ambulatory, largely nonverbal, presented no self-help skills other than feeding, and exhibited stereotypic behaviors commonly found among this population. Prior to training, two subjects were hospitalized and not replaced. The remaining subjects were evenly and randomly divided into experimental and control groups. Table 1 reports pertinent subject data. No significant differences were found between group means on any of the variables; neither group differed appreciably from the Pechacek et al. (1973) groups, with the exception that both present groups had substantially longer histories of institutionalization.

\section{Procedure}

The subjects were pre- and posttested in front of a mirror, just as in the earlier study. Photographic testing was conducted on a pre-, mid-, and posttraining basis using the two types of photographs described above: Each subject was given three trials with each stimulus set, for a total of six trials per testing session; order of presentation of type of stimuli was alternated over sessions and the relative position of the peer and selfphotographs was altered each trial, such that no self-photograph occupied the same position during any three trials.

Training was similar to that conducted in the earlier study, 
Table 1

Subject Data

\begin{tabular}{lccc}
\hline \multicolumn{1}{c}{ Group* } & Range & M & SD \\
\hline \multirow{4}{*}{ Experimental } & \multicolumn{3}{c}{ Social Quotient } \\
Control & $06-15$ & 10.44 & 2.39 \\
\multicolumn{4}{c}{ Chronological Age } \\
Experimental & $19.33-27.92$ & 23.15 & 2.77 \\
Control & $19.67-28.00$ & 21.94 & 3.08 \\
& \multicolumn{4}{c}{ Length of } & Institutionalization \\
Experimental & $05.50-14.71$ & 11.69 & 2.64 \\
Control & $05.17-13.25$ & 10.90 & 2.45 \\
\hline
\end{tabular}

$*_{n}=9$ per group

with the exception of the three-mirror display (similar to those found in clothing stores) used during the last training week.

\section{RESULTS}

No subject, regardless of treatment, brushed the dye marker during the posttest, even though one control subject $\left(\mathrm{S}_{16}\right)$ did so during pretesting.

On the photographic measures, in 18 total trials, only one subject $\left(\mathrm{S}_{16}\right)$ chose his self-photograph on as many as 9 . Only half of the subjects chose their picture on six trials, or at chance level. As Table 2 indicates, the control group chose more self-photographs; however, the difference between group means was not statistically significant $(t=.97, \mathrm{df}=16, \mathrm{p}>.15)$. Furthermore, the data reveal no differences between whole-body and head-and-shoulders pictures.

\section{DISCUSSION}

The modifications used in the present study obviously did not facilitate self-recognition. Results obtained are in accord with those reported by Pechacek et al. (1973): The institutionalized PMR males studied were incapable of recognizing their mirrored and photographic images as operationally assessed. Similar results were obtained in a French "field study" in which 15 female retardates (MA .75 to 3.33) demonstrated equivocal reactions when placed in front of a mirror (Shentoub, Soulairac, \& Rustin, 1955).

Table 2

Self-Photograph Choices

\begin{tabular}{lcrrrrrrr}
\hline & \multicolumn{2}{c}{ Whole-Body } & & \multicolumn{3}{c}{ Head-and-Shoulders } & & \multicolumn{2}{c}{ Total } \\
\cline { 2 - 5 } \multicolumn{1}{c}{ Group } & $\mathrm{M}$ & SD & & $\mathrm{M}$ & SD & & M & SD \\
\hline Experimental & 2.22 & .79 & & 2.00 & 1.15 & 4.22 & 1.40 \\
Control & 3.33 & .69 & & 3.56 & .94 & 6.89 & 1.10 \\
Total & 2.78 & .91 & & 2.78 & 1.31 & 5.56 & 1.82 \\
\hline
\end{tabular}

Collectively, these findings indicate that, for these subjects, mirror-image stimulation is not intrinsically reinforcing, as predicted by Gallup (1968), and that PMRs rank somewhat below adolescent chimpanzees (Gallup, 1970; Gallup, McClure, Hill, \& Bundy (1971) and orangutans (Lethmate \& Dücker, cited in Gallup, Boren, Gagliardi, \& Wallnau, in press) in the ability to make "self-directed" responses in the presence of a mirror. Similar negative results were obtained when a crabeating macaque was given $2,400 \mathrm{~h}$ of mirror exposure (Gallup, in press). Normal human infants with MAs comparable to those of the present subjects have been found to demonstrate mirrorimage recognition (Boulanger-Balleyguier, 1964; Gesell \& Ames, 1947; Stone \& Church, 1968), although these results have been questioned for methodological reasons (Gallup, 1975).

As to photographic recognition, it is evident that mirror training did not result in improved performance. The experimental group performed poorer than by chance and poorer than subjects receiving no training. Unfortunately, normative data as to the emergence of photugraphic self-recognition is not available; the youngest normals so tested were 5.4 years old (Gellert, Girgus, \& Cohen, 1971).

In summary, human PMR subjects do not demonstrate selfrecognition using training sessions of the length described and testing procedures suggested by ethological research. It appears that longer training periods must be used or other testing procedures devised.

\section{REFERENCES}

Boulanger-Balleyguier, G. Premières reactions devant le miroir. Enfance, 1964, 17, 51-67.

GalluP, G. G., JR. Mirror-image stimulation. Psychological Bulletin, 1968, 70, 782-793.

GalluP, G. G., JR. Chimpanzees: Self-recognition. Science, 1970 , 176, 86-87.

GalluP, G. G., JR. Towards an operational definition of selfawareness. In R. H. Tuttle (Ed.), Socio-ecology and psychology of primates. The Hague, Netherlands: Mouton, 1975.

Gallup, G. G., JR. Absence of self-recognition in a monkey (Macaca fascicularis) following prolonged exposure to a mirror. Developmental Psychobiology, in press.

Gallup, G. G., JR., Boren, J. L., Gagliardi, G. J., \& Wallnau, L. B. A mirror for the mind of man, or will the chimpanzee create an identity crisis for Homo sapiens. Journal of Human Evolution, in press.

Gallup, G. G., Jr., McClure, M. K., Hill, S. D., \& Bundy, R. A. Capacity for self-recognition in differentially reared chimpanzees. Psychological Record, 1971, 21, 69-74.

Gellert, E., Girgus, J. S., \& Cohen, J. Children's awareness of their body appearance: A developmental study of factors associated with the body percept. Genetic Psychology Monographs, 1971, 84, 109-174.

Gesell, A., \& Ames, L. B. The infant's reaction to his mirror image. Journal of Genetic Psychology, 1947, 70, 141-154.

Pechacek, T. F., Bell, K. F., Cleland, C. C., Baum, C., \& BOYLE, M. Self-recognition in profoundly retarded males. Bulletin of the Psychonomic Society, 1973, 1, 328-330.

Shentoub, S. A., Soulairac, A., \& Rustin, E. Compartement de l'enfant arriéré devant le mirior. Enfance, 1955, 7, 333-340.

Stone, L. J., \& ChURCh, J. Childhood and adolescence: $A$ psychology of the growing person (2nd ed). New York: Random, 1968.

(Received for publication August 10, 1976.) 